\title{
Damage in CFRPs due to low velocity impact at low temperature
}

\author{
T. Gómez-del Río, R. Zaera, E. Barbero, C. Navarro* \\ Department of Continuum Mechanics and Structural Analysis, Carlos III University of Madrid, Avda. de la Universidad 30, \\ 28911 Leganés, Madrid, Spain
}

\begin{abstract}
This work examines the response of carbon fibre reinforced epoxy matrix (CFRP) laminates at low impact velocity and in low temperature conditions. Square specimens of carbon fibre/epoxy laminates with different stacking sequences (unidirectional, cross ply, quasi isotropic and woven laminates) were tested using a Drop Weight Tower device. The test temperature ranged from 20 down to $150{ }^{\circ} \mathrm{C}$. After the impact tests, the damage extension was measured by C Scan ultrasonic inspection and the damage mechanisms were studied by optical and scanning electron microscopy. Results showed the influence of temperature, of ply reinforcement architecture and of stacking sequence on the mechanical behaviour of the CFRP laminates subjected to low velocity impulsive loads.
\end{abstract}

Keywords: Composite

\section{Introduction}

Carbon fibre reinforced plastics (CFRPs) are widely used in aeronautics and aerospace industry, on account of their high stiffness and strength as well as their low density. These materials present specific properties such as stiff ness/weight and strength/weight ratios higher than those of metallic materials. However, mechanical or structural components made of composite materials may suffer large damage extension when subject to impact loads, with the corresponding decrease of their residual strength and the subsequent risk of structural failure under service loads. The decrease in mechanical properties after impact was identified years ago [1], and studies have tried to answer two main questions: how damage appears under impact conditions, and once damage has appeared, how it spreads when static or cyclic loading are acting on the structural component. The answers have led to a better understanding of the damage micromechanisms in impact loading conditions, related to the basic properties of resin, fibres, fibre matrix interfacing effects and the architecture of the laminate $[2,3]$.

\footnotetext{
* Corresponding author. Tel.: + 3491624 9491; fax: +34916249430.

E-mail address: navarro@ing.uc3m.es (C. Navarro).
}

There are many studies of the behaviour of carbon fibre/epoxy laminates subjected to impact loads (see the excellent review papers of Cantwell and Morton [4] and Abrate [5,6]). The first step in studying the impact behaviour of composite materials is to characterize the type and extension of the damage induced in the structural member. Several damage mechanisms may appear in composite material components: fibre fracture, matrix cracking, fibre pull out and delamination [7 12]. This last failure mode is typical of CFRPs and is caused mainly by the interlaminar stresses generated between plies of different fibre orientation and thus showing different flexural behaviour. Moreover, it greatly contributes to decrease the strength of the laminate, given that the different plies no longer work together. Therefore, the threshold energy, that is, the impact energy below which no apparent damage is induced within the laminate, as well as the damage extent for a given impact energy above this threshold, are of great practical interest.

Furthermore, the aforementioned problem could be associated in the aeronautics and aerospace industries to the specific behaviour of the composite material at very low temperatures. CFRP structural components can suffer high velocity impact at cryogenic temperatures. Such is the case of high flying aircrafts $\left(60{ }^{\circ} \mathrm{C}\right.$ ) and spacecraft orbiting 
around the Earth $\left(150^{\circ} \mathrm{C}\right.$ when not directly exposed to solar radiation). Combat aircrafts may suffer ballistic impact; commercial aircrafts may be subjected to ballistic impact by a terrorist attack inside the plane; spacecraft may be impacted by space debris. In addition to these examples, cryogenic tanks can suffer low velocity impact during maintenance operations. The behaviour of carbon fibre composites under these thermal and loading conditions did not obtained enough attention in the open literature. Most of the reports related to low temperature have studied the static behaviour [13 19]. But few have considered the effect of impact on composite laminates: Kwang Hee et al. [20] analyzed the damage produced by impacts in CFRPs down to $30{ }^{\circ} \mathrm{C}$ and López Puente et al. [21] extended this analysis down to $150{ }^{\circ} \mathrm{C}$. Both of them focused their work on high velocity perforating impacts (from 100 to $500 \mathrm{~m} / \mathrm{s}$ ), far away from the threshold impact energy. Moreover, when perforation occurs the effect of the impact is highly localized around the contact area, leading to a smaller extension of the delamination. Therefore, the development and evolution of damage in carbon fibre/epoxy laminates subjected to low velocity impact at low temperature is still an open question.

This paper summarizes the results of low velocity impact tests carried out at different temperatures ranging from 20 to

$150{ }^{\circ} \mathrm{C}$ on CFRP laminates. A wide destructive and non destructive evaluation of the impact induced damage in the coupons clearly showed how temperature has an influence on the damage severity in carbon fibre composites. The analysis of the force displacement curves obtained from drop weight tower tests allowed also to measure the effect of temperature on the threshold impact energy. The exper imental tests were carried out for different fibre reinforce ment architecture and stacking sequence; each of them showed a specific behaviour under such thermal and loading conditions. In addition, the effect of thermal induced stresses on the damage is also examined.

\section{Materials and specimen geometry}

From tape prepregs of AS4 carbon fibre and 35016 epoxy manufactured by Hexcel, different panels were prepared: unidirectional $[0]_{10}$, cross ply $[0 / 90]_{3 s}$ and quasi isotropic $[ \pm 45 / 0 / 90]_{s}$ laminates. Plain woven pre pregs, AGP193 PW AS4 fibre and 8552 epoxy, manufac tured by Hexcel, were also used to make $[(0)]_{10}$ panels. Both resins have very similar mechanical properties. All laminates were manufactured by SACESA (Spain) follow ing standard requirements of the aeronautical industry. The resulting laminates had a volume fibre content of $60 \%$. The mechanical properties of the plies and thicknesses of the laminates are summarized in Tables 1 and 2. For low velocity impact tests, square specimens of $80 \times 80 \mathrm{~mm}^{2}$ were cut from the composite panels by a water jet device.
Table 1

Mechanical properties of unidirectional and woven ply at room temperature (Hexcel composites)

\begin{tabular}{lcc}
\hline Property & Tape AS4/35016 & Woven AS4/8552 \\
\hline $0^{\circ}$ Tensile modulus $(\mathrm{GPa})$ & 131 & 68 \\
$90^{\circ}$ Tensile modulus $(\mathrm{GPa})$ & 9 & 68 \\
Shear modulus $(\mathrm{GPa})$ & 7.2 & 3.7 \\
$0^{\circ}$ Tensile strength $(\mathrm{MPa})$ & 2137 & 795 \\
$90^{\circ}$ Tensile strength $(\mathrm{MPa})$ & 80 & 795 \\
Shear strength $(\mathrm{MPa})$ & 105 & 98 \\
\hline
\end{tabular}

Table 2

Specimens thicknesses

\begin{tabular}{ll}
\hline Laminate & Thickness (mm) \\
\hline Unidirectional & 2.0 \\
Cross ply & 2.3 \\
Quasi isotropic & 1.6 \\
Woven & 2.2 \\
\hline
\end{tabular}

\section{Low velocity impact tests}

\subsection{Experimental device and test conditions}

Low impact tests at different temperatures were carried out by means of the instrumented Drop Weight Tower device (CEAST, Fractovis 6875) which has a climatic chamber, as sketched in Fig. 1. Specimens were placed inside the chamber on a steel support and clamped along their outer border in such a way that a circular laminate area of $60 \mathrm{~mm}$ in diameter was the effective free laminate surface. Slight modifications were made to the climatic chamber to reach temperatures as low as $150{ }^{\circ} \mathrm{C}$. A thermocouple was connected to a temperature controller regulating the opening of an electrovalve, which allowed a controlled volume of liquid nitrogen to enter the chamber. Once the desired temperature was reached in the chamber, the cooling system keep it enough time before impact to ensure that CFRP specimen and inner atmosphere remained at the test temperature (Fig. 2). The total specimen cooling time was deduced from numerical thermal analysis, which gave $20+5 \mathrm{~min}$ to reach $60^{\circ} \mathrm{C}$ and $45+10 \mathrm{~min}$ to reach $150{ }^{\circ} \mathrm{C}$.

The cylindrical striker bar weighed $3.62 \mathrm{~kg}$ and had a semi spherical nose $20 \mathrm{~mm}$ in diameter at its edge, which impacted orthogonally to the specimen. A load cell placed on the striker sent the force versus time signal to an acquisition data system. After impact, an anti rebound system held the striker to avoid multi hits on the specimen. For cross ply, quasi isotropic and woven laminates, four impact energies were chosen between damage threshold and perforation. The unidirectional laminates broke into two at the four impact energies considered, its fracture surface running parallel to the fibre direction. After several trial 


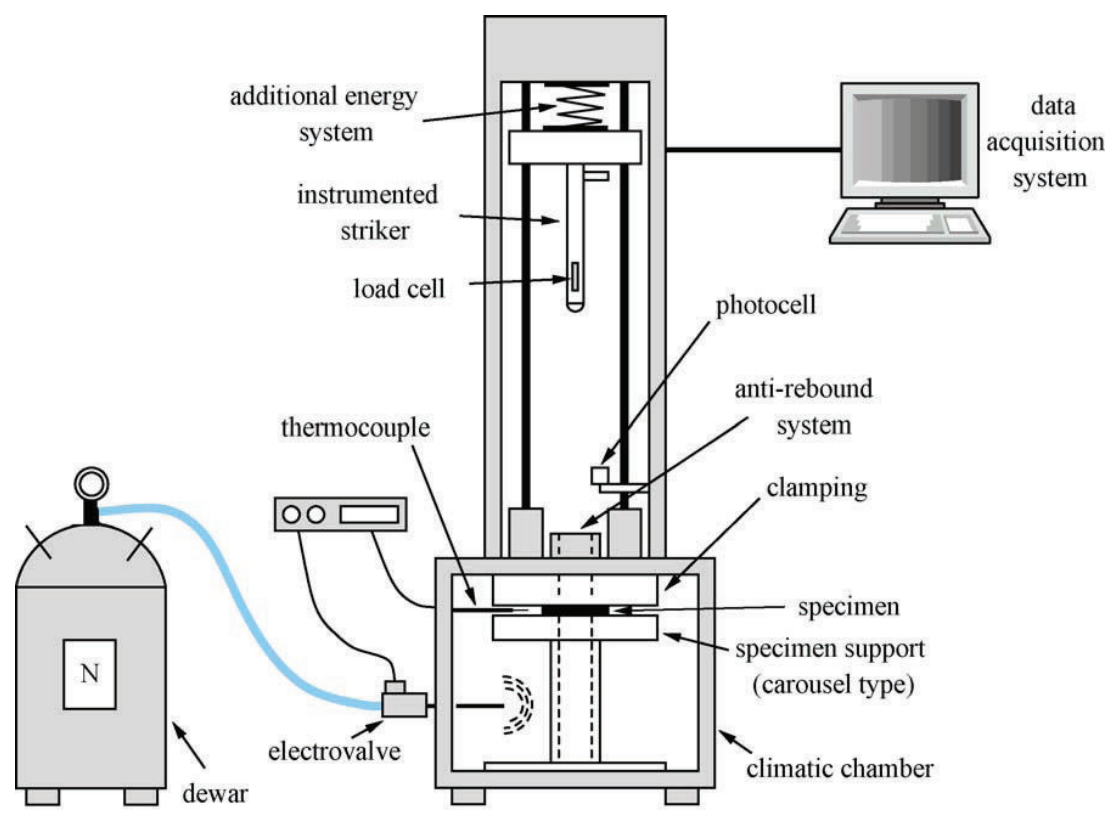

Fig. 1. Sketch of the modified drop weight tower CEAST Fractovis 6875 with the cooling system.

tests, the energies shown in Table 3 were selected for the tests. For each laminate type, three different test tempera tures: 20, $\quad 60$ and $150{ }^{\circ} \mathrm{C}$ were adopted. Five tests were made for each type of laminate, and each energy and temperature.

\subsection{Test results}

Due to the technical difficulties of measuring in low temperature conditions the displacement $x$ of the specimen midspan section, this was derived from the impact force $F(t)$ exerted by the striker on the specimen. Assuming full contact between striker and specimen throughout the experiment, $x$ may be obtained as

$x(t)=\int_{0}^{t}\left[v_{0}+\int_{0}^{\tau} \frac{P}{m} \mathrm{~F}(\theta) \mathrm{d} \theta\right] \mathrm{d} \tau$

where $t$ is the time from the instant at which the striker bar hits the specimen, $m$ and $P$ the striker bar mass and weight, and $v_{0}$ the striker initial velocity at the beginning of the experiment $(t=0)$. During the test, the energy transmitted to the specimen $E$ at any time may be approached

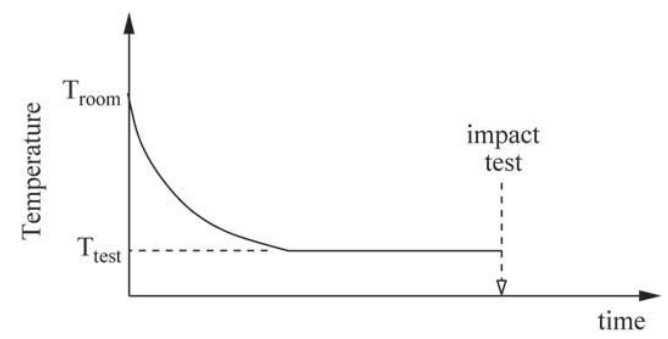

Fig. 2. Temperature history inside the climatic chamber before impact. by using Eq. (2)

$E(t)=\int_{0}^{t} F \mathrm{~d} x=\int_{0}^{t} F(\tau)\left[v_{0}+\int_{0}^{\tau} \frac{P \quad F(\theta)}{m} \mathrm{~d} \theta\right] \mathrm{d} \tau$

Fig. 3 shows a typical impact energy time history when no penetration of the laminate occurs. The beginning of the plateau of the curve coincides with the loss of contact between the striker and the specimen, so, this energy coincides with that absorbed by the specimen. This latter energy has several components: kinetic and elastic energies, and absorbed energy due to laminate damage. It is commonly assumed that in this type of material the first two energies are much lower than the third one, so the total absorbed energy practically coincides with the energy dissipated by damage to the laminate. Figs. 46 show, respectively, for cross ply, quasi isotropic and woven laminates, the mean values of absorbed energy versus impact energy at each test temperature (standard deviation less than $9 \%$ ). Unidirectional $[0]_{10}$ laminates broke into two pieces when impacted at all the considered energies. This energy increases as temperature decreases. This observation applies to all tape laminates and impact energies. Woven laminates does not show this trend: excluding the tests done under higher impact energies at

$150{ }^{\circ} \mathrm{C}$, the absorbed energy is less than that measured at

Table 3

Test impact energies in the different configurations of CFRP laminates

\begin{tabular}{lllrr}
\hline Laminate & \multicolumn{4}{l}{ Impact energy (J) } \\
\hline Unidirectional $[0]_{10}$ & 2 & 3 & 4 & 5 \\
Cross ply [0/90] $]_{s s}$ & 1 & 3 & 4 & 6 \\
Quasi isotropic $[ \pm 45 / 0 / 90]_{s}$ & 2 & 3 & 4 & 5 \\
Woven $[(0)]_{10}$ & 4 & 7 & 10 & 13 \\
\hline
\end{tabular}




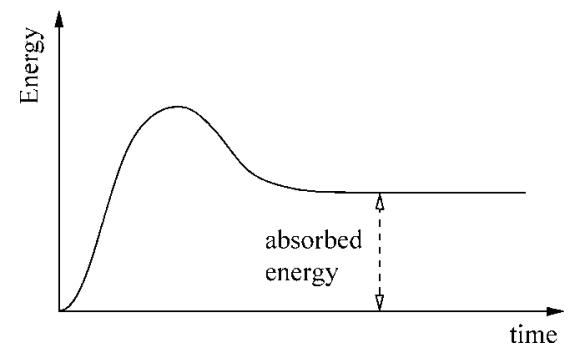

Fig. 3. Typical transmitted energy vs time curve for non penetration impact.

room temperature. This was the first difference observed between tape and woven laminates.

No clear influence of temperature on the energy absorbed by CFRP specimens can be derived, however. To know whether the temperature has a clear effect on damage extension, a close inspection of the specimens was made and the results are given below.

\section{Damage evaluation}

Several destructive and non destructive damage inspec tion techniques have been used on composite materials [5,22 24]. These techniques may provide information about the location and size of the damage in one, two or three dimensions. Ultrasonic techniques (B Scan and C Scan) are clearly the most used in detecting damage in CFRPs [25,26], but they give an image of the overall damage, and the different damage mechanisms are difficult to identify. So destructive inspection of the specimen is often used in conjunction with scanning techniques to get fuller information about the damage mechanisms.

To determine the type and extension of damage in the CFRP specimens, visual inspection and $\mathrm{C}$ scanning using an ultrasonic device manufactured by Ultrasonic Science Ltd were performed. Once the damage extension was measured, the specimens were cut through their centre lines by a diamond yarn cutter. The resulting cross sections were examined by optical microscopy (Nikon Epinot micro scope) to observe the different types of generated damages, and also scanning electron microscopy was used to study the delaminated surfaces.

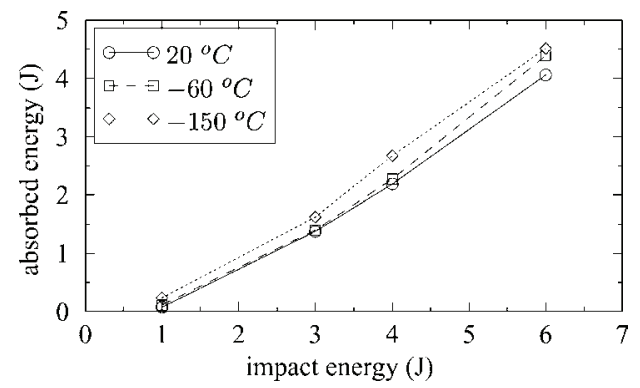

Fig. 4. Mean values of absorbed energy vs impact energy. Cross ply laminate.

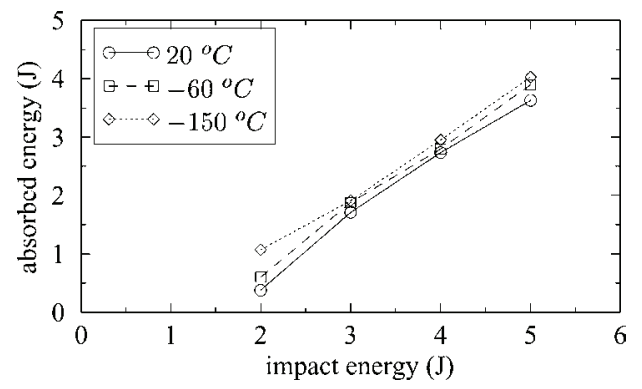

Fig. 5. Mean values of absorbed energy vs impact energy. Quasi isotropic laminate.

\subsection{Visual inspection}

External damage caused by the impact is observed by visual inspection of the specimens. On one hand, the impacted face of the specimen (the one on which the striker bar contacts) shows a concave indentation caused by the edge of the striker bar. The curvature of the indentation zone coincides with that of the striker tip. Indentation grows as impact energy increases and as temperature decreases. The depth of the indentation measured for each specimen varied between no indentation (cross ply laminate impacted with $1 \mathrm{~J}$ at $20^{\circ} \mathrm{C}$ ) and $1.1 \mathrm{~mm}$ (woven laminate tested with impact energy of $13 \mathrm{~J}$ at $150{ }^{\circ} \mathrm{C}$ ). In all the laminates and test temperature conditions, fibre fracture and matrix cracks transverse to the fibres are seen in the indentation crater at the highest impact energies. At these energy levels and at the lowest temperatures, damage was also observed on the rear face of the specimen (quasi isotropic laminate tested at 4 and $5 \mathrm{~J}$ and temperatures of 60 and $150{ }^{\circ} \mathrm{C}$, cross ply for $6 \mathrm{~J}$ at $150{ }^{\circ} \mathrm{C}$, woven laminate for 10 and $13 \mathrm{~J}$ at all temperatures). On the rear face of the specimen, matrix cracking, fibre fracture and fibre pull out concen trated on a large zone centered around the impact line. Figs. 7 and 8 show, in a quasi isotropic laminate, the effect of the low temperature on the external extension of the damaged zone.

\subsection{Scan inspection}

An image of the damage extension was obtained by C Scan of each impacted specimen. As an example,

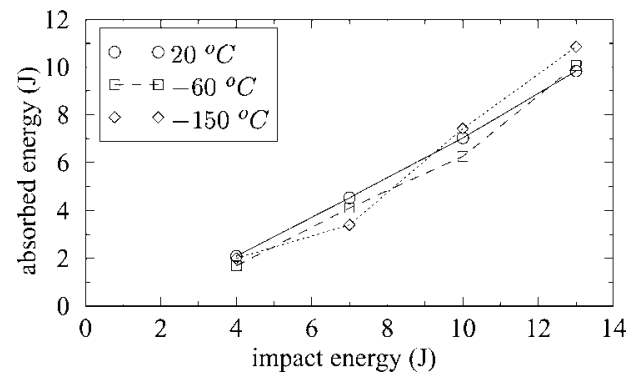

Fig. 6. Mean values of absorbed energy vs impact energy. Woven laminate. 


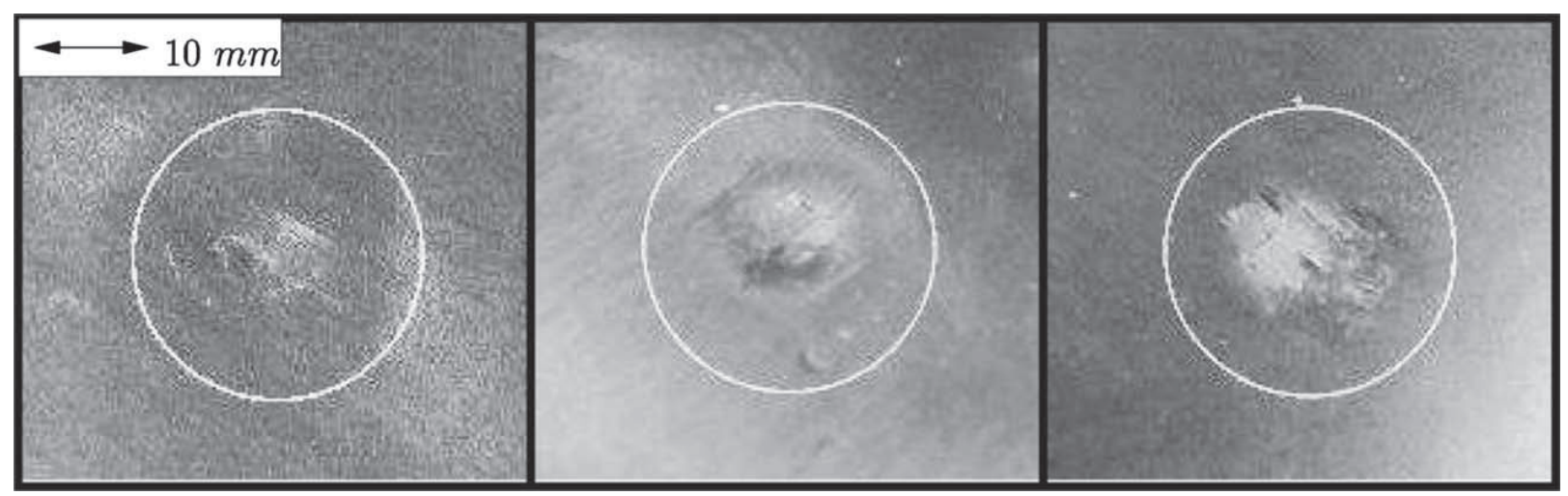

Fig. 7. Effect of the temperature on the impacted side damage. Quasi isotropic laminate impacted at 5 J. 20 (left), - 60 (center) and - $150{ }^{\circ} \mathrm{C}$ (right).

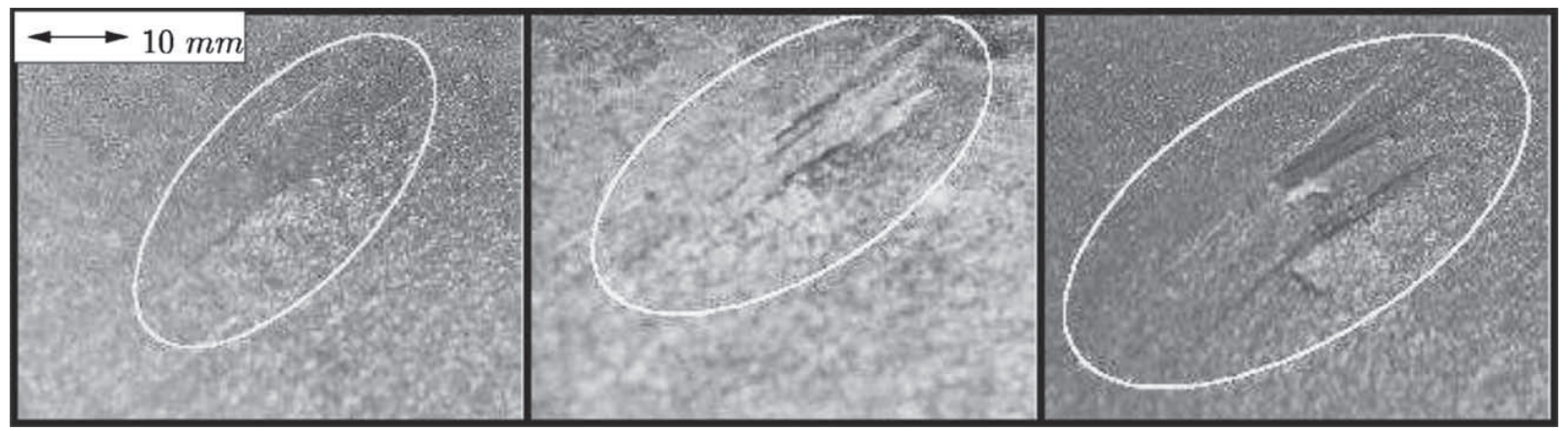

Fig. 8. Effect of the temperature on the rear side damage. Quasi isotropic laminate impacted at 5 J. 20 (left), -60 (center) and $-150{ }^{\circ} \mathrm{C}$ (right).

Figs. 912 show damage images of cross ply, quasi isotropic and woven laminates impacted at $4 \mathrm{~J}$ and at different temperatures. The shape of the overall delaminated area is consistent with Clark's theory [27], that predicts an ellipse with its major axis lying along the fibre direction of the lower ply. In cross ply and quasi isotropic laminates the damaged area increases as temperature decreases, whereas in woven laminates the influence of temperature is less than that observed in the other laminate types. Because delamination occurs mainly between plies with different fibre orientations, unidirectional laminates do not develop this kind of damage: the $[0]_{10}$ laminate broke into two pieces, showing slight delamination and matrix cracking near the fracture surface.

In each C Scan image, the damaged area was measured. Figs. 1315 show the mean values of damage area versus impact kinetic energy at the three temperatures considered in cross ply, quasi isotropic and woven laminates (standard deviation less than 13\%). Two important observations were: firstly, at a given impact energy, the delamination area increases as the temperature becomes lower. Sec ondly, by comparison of Figs. 13 and 14 with Fig. 15, a lower increase of damaged area as temperature decreases is observed in woven laminates than in the other two laminate

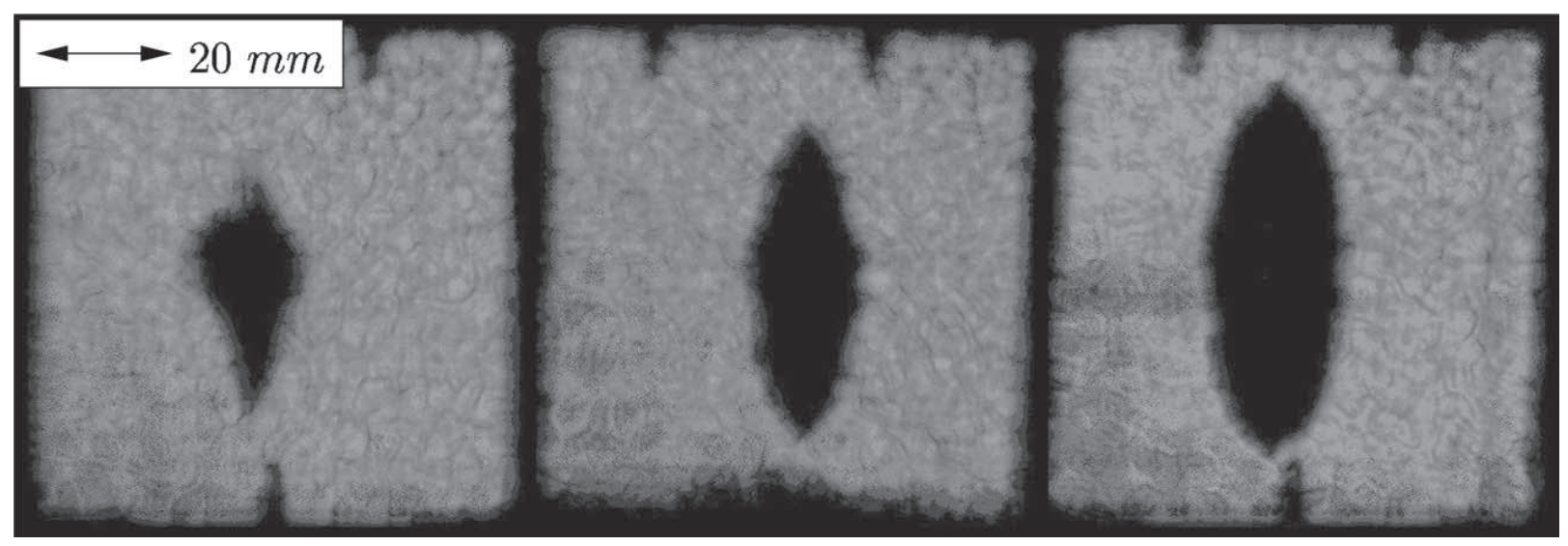

Fig. 9. C Scan image showing damage extension in the cross ply laminate impacted at 4 J. 20 (left), -60 (center) and $-150{ }^{\circ} \mathrm{C}$ (right). 


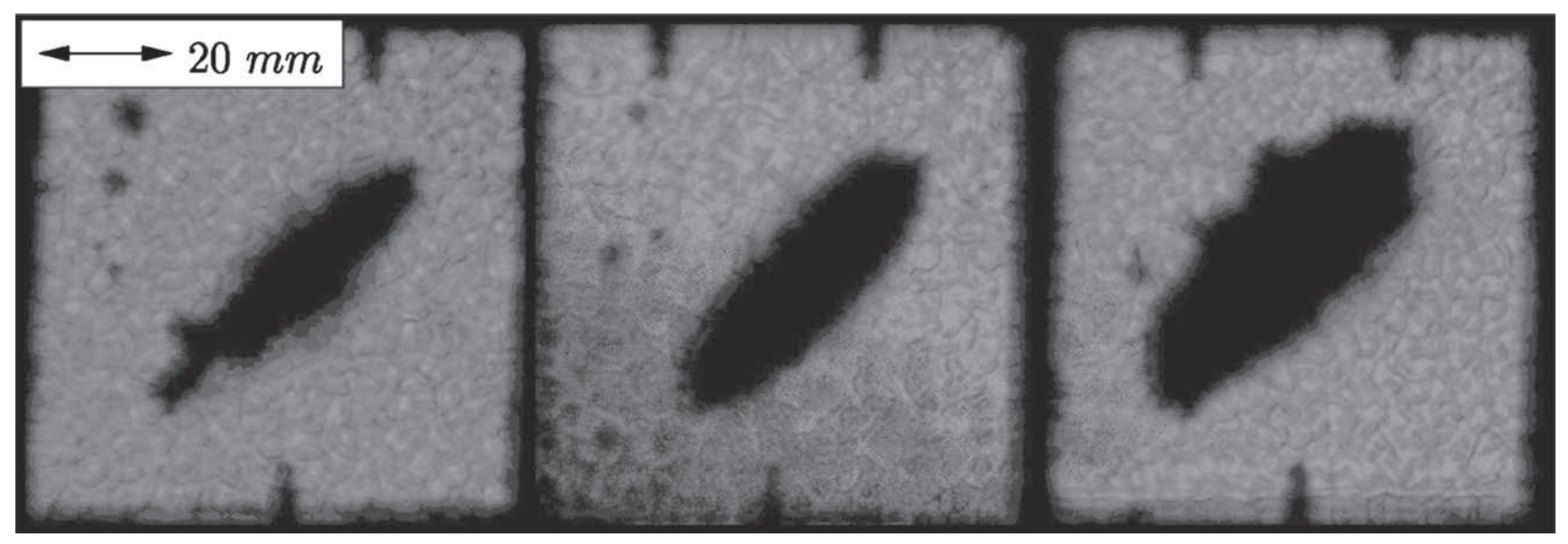

Fig. 10. C Scan image showing damage extension in the quasi isotropic laminate impacted at 4 J. 20 (left), -60 (center) and $-150{ }^{\circ} \mathrm{C}$ (right).

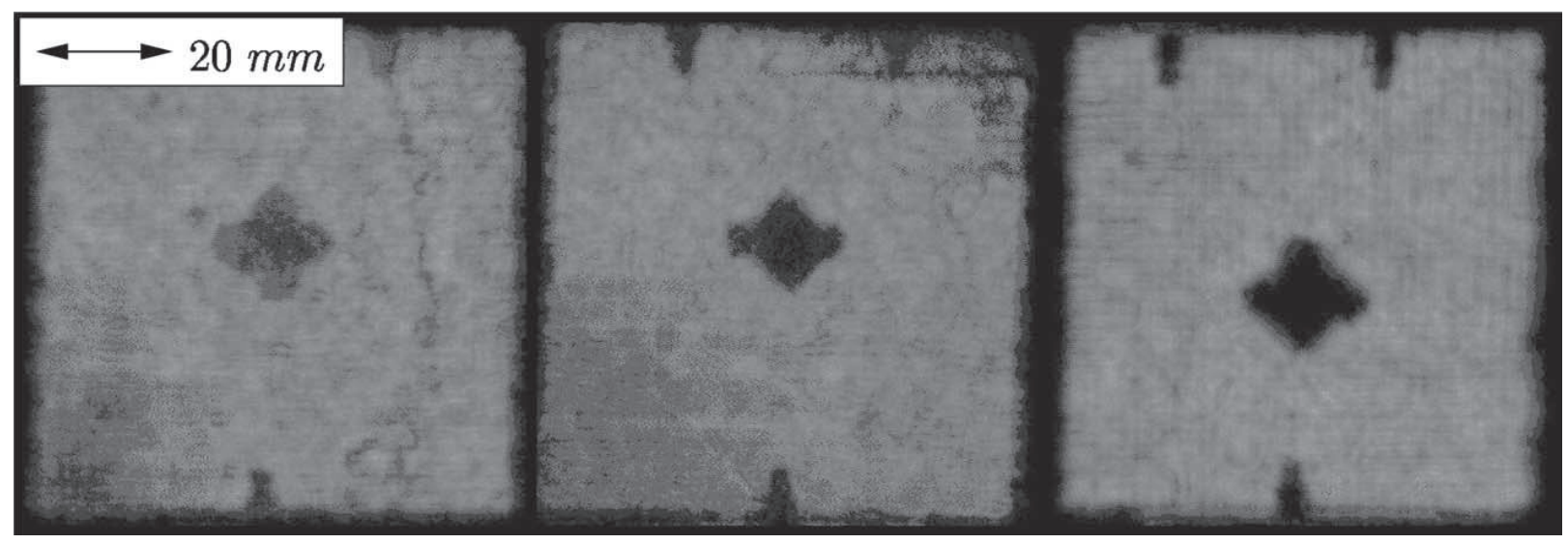

Fig. 11. C Scan image showing damage extension in the woven laminate impacted at $4 \mathrm{~J} .20$ (left), -60 (center) and $-150{ }^{\circ} \mathrm{C}$ (right).

types. This could also be deduced by the inspection of Figs. 911.

It is also interesting to check the influence of temperature on the first damage threshold energy, that is, the impact energy below which no apparent damage is induced within the laminate. This could be determined by reducing the test energy until no damage was observed in the specimen.
Alternatively, some authors [28] propose the load dis placement curve of the impact test to obtain the threshold. In all the laminates and test temperature conditions, the load increases linearly with displacement until it reaches a peak. As an example, Fig. 16 shows the typical force displace ment curves of the tests. Then small reversals occur, indicating that damage is being generated in the material.

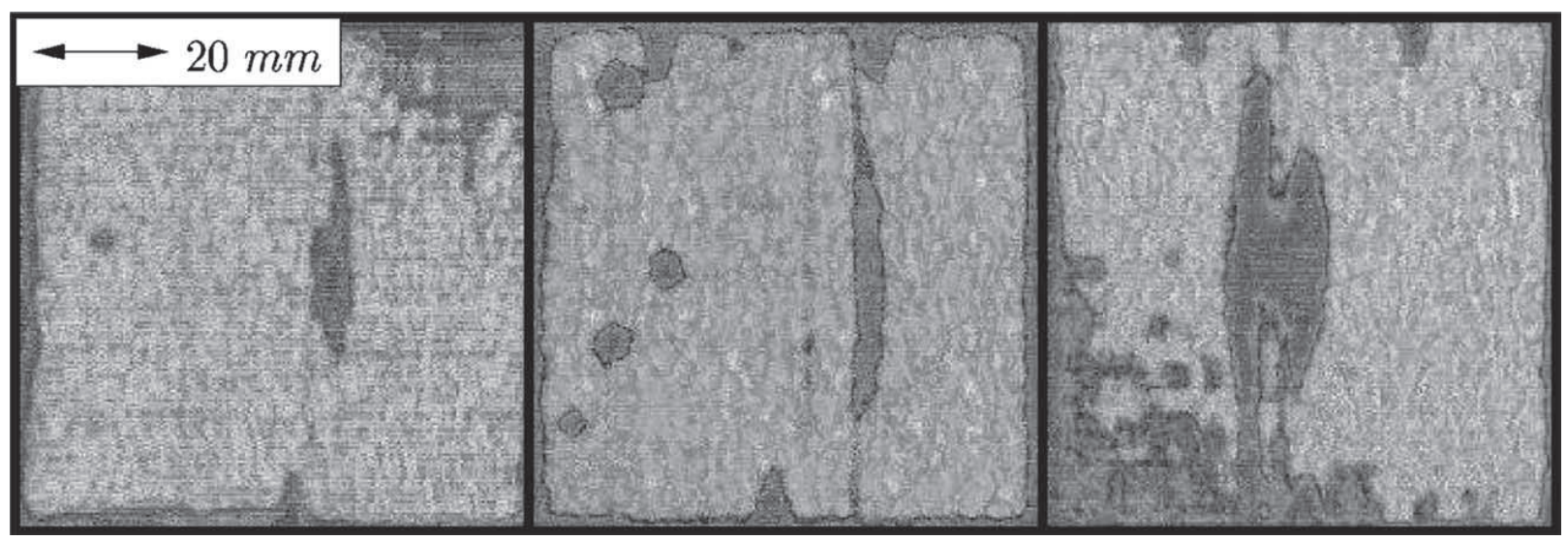

Fig. 12. C Scan image showing damage extension in the unidirectional laminate impacted at 4 J. 20 (left), -60 (center) and $-150{ }^{\circ} \mathrm{C}$ (right). 


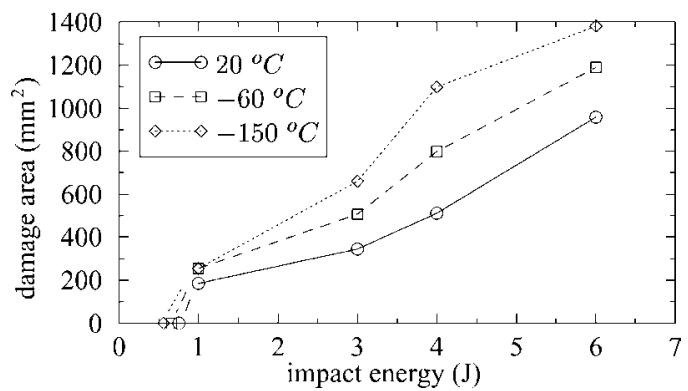

Fig. 13. Damage area vs impact energy. Cross ply laminate.

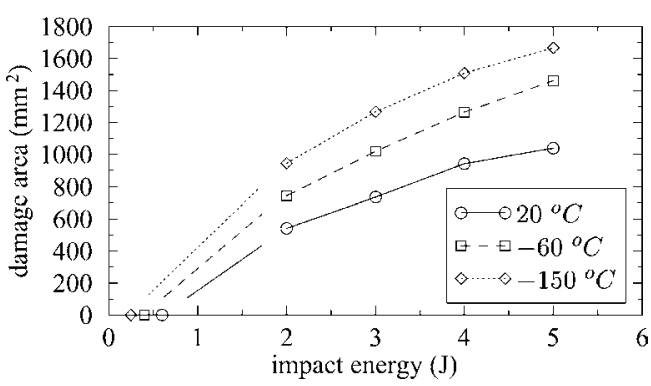

Fig. 14. Damage area vs impact energy. Quasi isotropic laminate.

The peak appears at the same load level under any impact energy. So threshold energy can be deduced by measuring the energy below the force time curve portion up to the first peak (onset of damage). In Figs. 1315 the threshold plotted in the tested laminates at different temperatures, shows that it decreases at lower temperatures.

\subsection{Microscopic inspection}

More information about damage caused to CFRP laminates was obtained by cutting the specimen through the impact point with a diamond yarn cutter and inspecting the cross section by optical microscopy. In unidirectional laminates, damage consisted mainly of matrix cracks, debonding and fibre failure (all of them increased with the impact energy). Little delamination was observed in this type of material. Matrix cracks of $45^{\circ}$ at low impact energies create an inverse pine tree, which characterizes thin laminate behaviour under impact loading [29]. As energy increases, these cracks join and produce delaminations

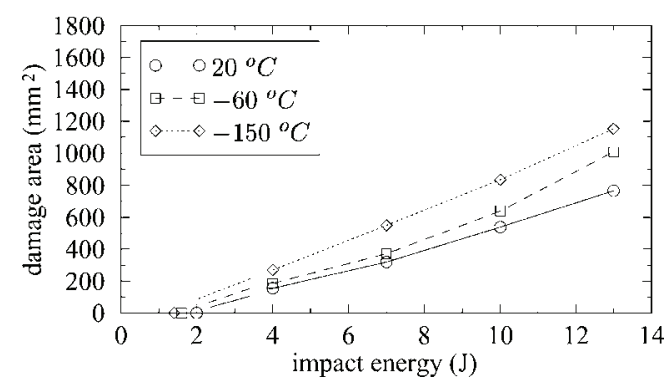

Fig. 15. Damage area vs impact energy. Woven laminate.

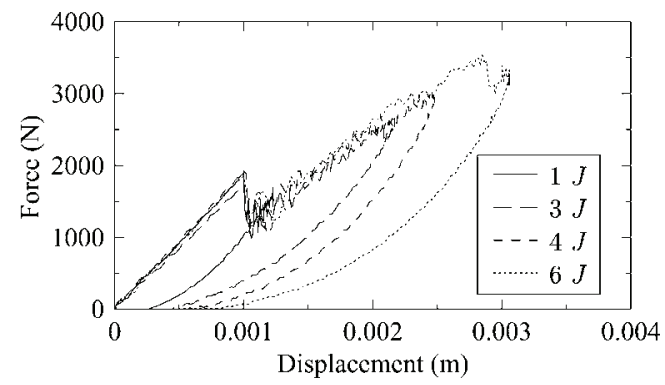

Fig. 16. Load vs displacement at different impact energies in the cross ply laminate tested at $20^{\circ} \mathrm{C}$.

and, finally, fibre fracture and fibre matrix debonding of the lower plies. This trend was observed when keeping the temperature constant and increasing impact energy. But it also appears in cross ply, quasi isotropic and woven laminates when keeping a constant impact energy and decreasing the temperature (Fig. 17): higher crack density, larger delamination areas, and fibre matrix debonding zones are observed at low temperature.

Delaminated surfaces were also observed by scanning electron microscopy. The fractographic study showed no noticeable change on the fracture surfaces with temperature. Delamination always produced the same pattern: separation of fibres and matrix, leaving carbon fibres in the lower ply and fibre marks in the upper ply (Fig. 18). Since damage extension significantly increases at low temperature (as observed by $\mathrm{C}$ Scan inspection and optical microscopy) and no differences were found in the fracture surface topography at 20, 60 and $150{ }^{\circ} \mathrm{C}$, the little influence of temperature on the energy absorbed by the laminate during impact may be due solely to the lower specific fracture energy of the material at low temperature.

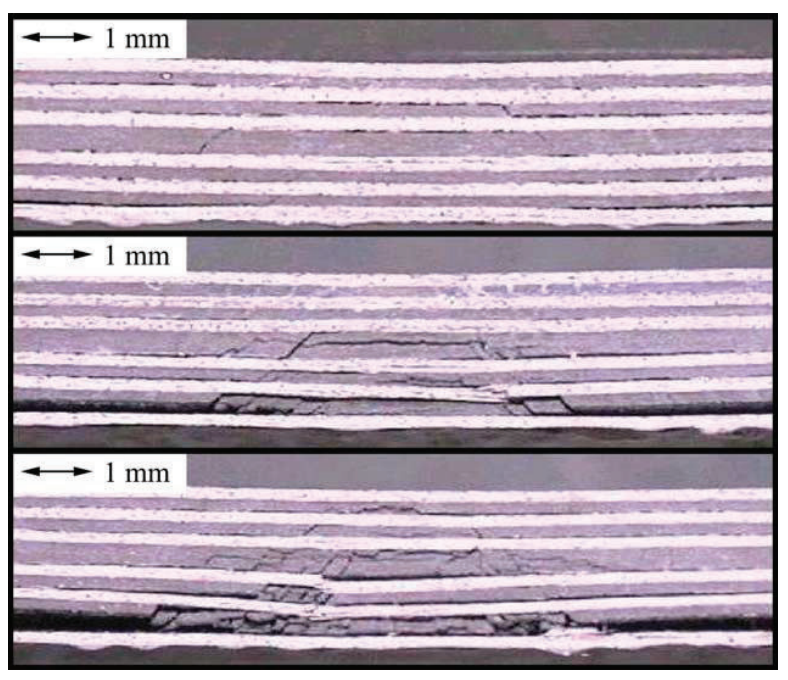

Fig. 17. Optical microscopy photographs of the section at the impact point of a cross ply laminate tested at $3 \mathrm{~J}$. 20 (up), -60 (center), $-150{ }^{\circ} \mathrm{C}$ (bottom). 


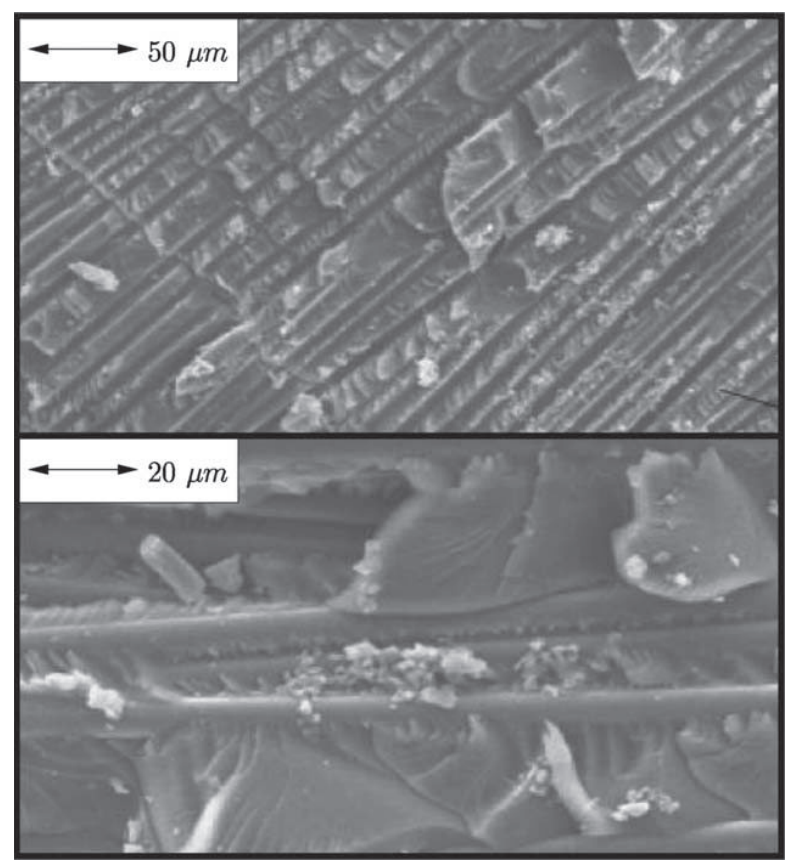

Fig. 18. Scanning electron microscopy images of the upper (top) and lower (bottom) surfaces of a delamination. Quasi isotropic laminate impacted at $-150{ }^{\circ} \mathrm{C}$.

\section{Interlaminar thermal stresses}

In tape CFRP plies, the thermal expansion coefficient in the direction of fibres $\alpha_{1}$ is normally much smaller than that in the transverse direction $\alpha_{2}$. In addition, the material stiffness in the fibre direction $E_{1}$ is much greater than that transverse to the fibres $E_{2}$. As the laminate is cooled from its cure temperature, each ply tends to contract in the transverse direction much more than in the fibre direction. However, this transverse contraction is constrained by the adjacent plies, and this produces inter ply stresses in the laminate. These thermally induced stresses may be great enough to generate interfacial debonding in the composite and nano cracks within the matrix during cool down. It may also influence the behaviour of the laminate under impact loads, so, it is interesting to know the internal stress states in the laminates at the temperatures involved in this work. Stresses in the cross ply and quasi isotropic laminates were calculated (for the woven laminate there is no mismatch in the thermal expansion coefficients $\alpha_{1}$ and $\alpha_{2}$ ), assuming that the laminate is stress free at its curing temperature $177^{\circ} \mathrm{C}$. In an orthotropic ply, the incremental stress strain relationship is given by the vector equation

$\{\Delta \sigma\}=[C]\left\{\Delta \varepsilon \quad \Delta \varepsilon^{\text {temp }}\right\}$

where $[C]$ is the ply stiffness matrix and the vectors $\{\Delta \sigma\}$, $\{\Delta \varepsilon\},\left\{\Delta \varepsilon^{\text {temp }}\right\}$ are, respectively, the stress, strain and free thermal strain increment vectors, defined as follows:

$\{\Delta \sigma\}^{\text {transp }}=\left(\Delta \sigma_{1}, \Delta \sigma_{2}, \Delta \sigma_{3}, \Delta \tau_{12}, \Delta \tau_{13}, \Delta \tau_{23}\right)$

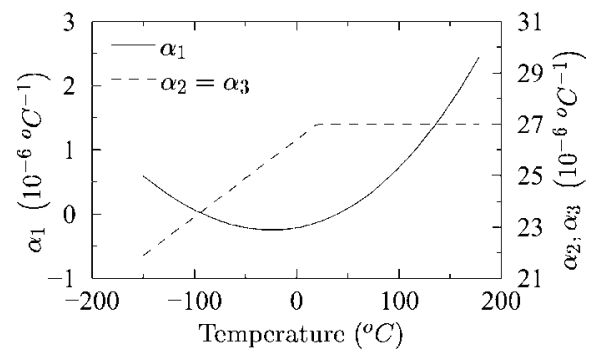

Fig. 19. Variation with temperature of thermal expansion coefficients of a tape ply.

$$
\begin{aligned}
& \{\Delta \varepsilon\}^{\text {transp }}=\left(\Delta \varepsilon_{1}, \Delta \varepsilon_{2}, \Delta \varepsilon_{3}, \Delta \gamma_{12}, \Delta \gamma_{13}, \Delta \gamma_{23}\right) \\
& \left\{\Delta \varepsilon^{\text {temp }}\right\}^{\text {transp }}=\left(\alpha_{1} \Delta T, \alpha_{2} \Delta T, \alpha_{2} \Delta T, 0,0,0\right)
\end{aligned}
$$

Considering deformation compatibility of all the plies, this constitutive equation permits a computation of the thermally induced stresses in the laminate. Given the great decrease of temperature, variations of the material elastic constants with temperature were assumed. The thermal expansion coefficients were determined in the AS4/35016 tape material by gluing two gages (VISHAY WK 00 250BG 350) on the same face of a unidirectional laminate, one in the fibre direction and another in the transverse direction, and measuring strains from 177 to

$150{ }^{\circ} \mathrm{C}$. After correcting the resistivity variation and the transverse deformation of the gauges with tempera ture, $\alpha_{1}$ and $\alpha_{2}$ were measured (Fig. 19). The elastic properties of the ply at low temperatures were obtained from the literature [13,14,30] (Figs. 20 and 21).

The stress strain relation of Eq. (3) was implemented into the commercial finite element code ABAQUS/Standard, and stresses in cross ply and quasi isotropic laminates were determined. $\sigma_{3}, \tau_{12}, \tau_{13}$ and $\tau_{23}$ were closed to zero, and $\sigma_{1}$ and $\sigma_{2}$ reached the same value in all the plies. Results of the thermally induced stresses are shown in Table 4. Some of these values could be considered relatively high if we think of their influence on the onset of damage during impact. This effect was analysed using the quadratic failure criteria of Hou et al. (2000). It considers four damage factors, namely fibre failure factor

$$
e_{\mathrm{f}}^{2}=\left(\frac{\sigma_{1}}{X_{\mathrm{T}}}\right)^{2}+\left(\frac{\tau_{12}+\tau_{13}}{S_{\mathrm{f}}}\right)^{2}
$$

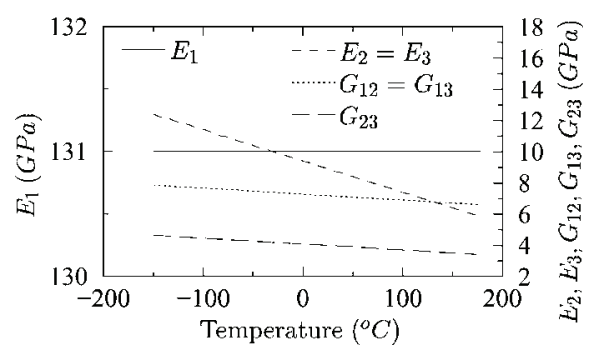

Fig. 20. Variation with temperature of elastic moduli of a tape laminate. 


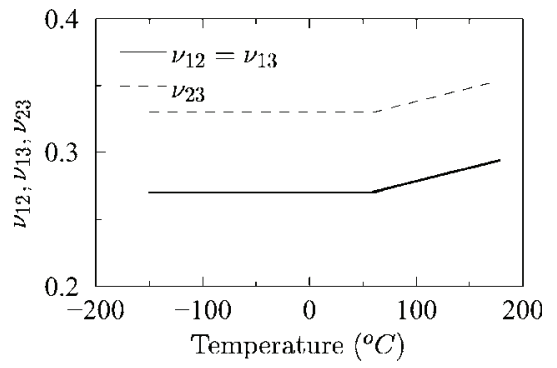

Fig. 21. Variation with temperature of Poisson coefficients of a tape laminate.

matrix cracking factor (for $\sigma_{2}>0$ )

$e_{\mathrm{m}}^{2}=\left(\frac{\sigma_{2}}{Y_{\mathrm{T}}}\right)^{2}+\left(\frac{\tau_{12}}{S_{12}}\right)^{2}+\left(\frac{\tau_{23}}{S_{\mathrm{m} 23}}\right)^{2}$

matrix crushing factor (for $\sigma_{2}<0$ )

$e_{\mathrm{d}}^{2}=\frac{1}{4}\left(\frac{\sigma_{2}}{S_{12}}\right)^{2}+\frac{Y_{\mathrm{C}} \sigma_{2}}{4 S_{12}^{2}} \quad \frac{\sigma_{2}}{Y_{\mathrm{C}}}+\left(\frac{\tau_{12}}{S_{12}}\right)^{2}$

and delamination factor (for $\sigma_{3}>0$ )

$e_{1}^{2}=\left(\frac{\sigma_{3}}{Z_{\mathrm{T}}}\right)^{2}+\left(\frac{\tau_{13}}{S_{13}}\right)^{2}+\left(\frac{\tau_{23}}{S_{123}}\right)^{2}$

where the meaning of the different parameters is summar ized in Table 5. Each failure type appears when the associated damage factor equals 1. The value of each damage factor was calculated in cross ply and quasi isotropic laminates at the three testing temperatures, using the strength values shown in Table 6 (assuming dependence on temperature observed in Refs. [14,16,17] and Hexcel Composites). Only $X_{\mathrm{T}}, Y_{\mathrm{T}}$ and $Y_{\mathrm{C}}$ were used, on account of

Table 4

Thermal induced stresses in the cross ply and quasi isotropic laminates

\begin{tabular}{lll}
\hline Temperature $\left({ }^{\circ} \mathrm{C}\right)$ & $-\sigma_{1} \approx \sigma_{2}(\mathrm{MPa})$ & \\
\cline { 2 - 3 } & Cross ply & Quasi isotropic \\
\hline 20 & 20 & \\
-60 & 40 & 24 \\
-150 & 75 & 42 \\
\hline
\end{tabular}

Table 5

Parameters in the Hou et al. (2000) failure criteria

\begin{tabular}{ll}
\hline Parameter & Mechanical property \\
\hline$X_{\mathrm{T}}$ & Tensile strength in direction 1 \\
$Y_{\mathrm{T}}$ & Tensile strength in direction 2 \\
$Y_{\mathrm{C}}$ & Compressive strength in direction 2 \\
$Z_{\mathrm{T}}$ & Tensile strength in direction 3 \\
$S_{12}$ & Shear strength in the plane 12 \\
$S_{13}$ & Shear strength in the plane 13 \\
$S_{\mathrm{f}}$ & Shear strength involving fibre failure \\
$S_{\mathrm{m} 23}$ & Shear strength for matrix cracking in the plane 23 \\
$S_{123}$ & Shear strength for delamination in the plane 23 \\
\hline
\end{tabular}

Table 6

Strengths in the Hou et al. failure criteria (2000) at different temperatures

\begin{tabular}{llll}
\hline Temperature $\left({ }^{\circ} \mathrm{C}\right)$ & \multicolumn{2}{l}{ Strengths $(\mathrm{MPa})$} & \\
\cline { 2 - 4 } & $X_{\mathrm{T}}$ & $Y_{\mathrm{T}}$ & $Y_{\mathrm{C}}$ \\
\hline 20 & 2137 & 80 & 160 \\
-60 & 2137 & 86 & 158 \\
-150 & 2138 & 97 & 155 \\
\hline
\end{tabular}

Table 7

Damage factors due to thermally induced stresses

\begin{tabular}{|c|c|c|c|c|c|c|c|c|}
\hline \multirow[t]{2}{*}{ Temperature $\left({ }^{\circ} \mathrm{C}\right)$} & \multicolumn{4}{|c|}{ Cross ply } & \multicolumn{4}{|c|}{ Quasi isotropic } \\
\hline & $e_{\mathrm{f}}^{2}$ & $e_{\mathrm{m}}^{2}$ & $e_{\mathrm{d}}^{2}$ & $e_{1}^{2}$ & $e_{\mathrm{f}}^{2}$ & $e_{\mathrm{m}}^{2}$ & $e_{\mathrm{d}}^{2}$ & $e_{1}^{2}$ \\
\hline 20 & $\approx 0$ & 0.06 & $\approx 0$ & $\approx 0$ & $\approx 0$ & 0.09 & $\approx 0$ & $\approx 0$ \\
\hline-60 & $\approx 0$ & 0.21 & $\approx 0$ & $\approx 0$ & $\approx 0$ & 0.23 & $\approx 0$ & $\approx 0$ \\
\hline-150 & 0.001 & 0.59 & $\approx 0$ & $\approx 0$ & 0.001 & 0.59 & $\approx 0$ & $\approx 0$ \\
\hline
\end{tabular}

the reduced values of the thermally induced stresses associated with the other strength parameters and the positive values of $\sigma_{2}$. The corresponding damage factors are given in Table 7. Although most of the factors present negligible values, that corresponding to matrix cracking could be relatively high before impact at low temperature $\left(60 \%\right.$ of the critical value at $150{ }^{\circ} \mathrm{C}$. This type of damage is the first to be generated during out of plane impulsive loading and also precedes delamination, so greater damage extension is expected in tape laminates when impacted at low temperatures. In the woven laminate considered in this work, no interlaminar thermally induced stresses appear, so damage increase at low temperature was lower. This agrees with experimental observations.

\section{Conclusions}

It is well stated that damage induced in CFRP laminates by low velocity impact loads (when no perforation occurs) increases with impact energy. The experimental results obtained in this work showed that cooling the laminate before impact has an effect on damage similar to that of increasing the impact energy: larger matrix cracking and delamination extension, deeper indentation on the impacted side, and more severe fibre matrix debonding and fibre fracture on the opposite side. Nevertheless, an essential difference between both damage increasing effects has been observed: whereas the energy absorbed by the laminate is roughly proportional to the impact energy, the larger extent of damage favoured by low temperature does not go with a greater dissipation of energy due to the lower specific fracture energy of the epoxy matrix at cryogenic conditions.

This embrittlement of the polymeric matrix, together with the interlaminar thermal stresses generated in the laminate at low temperature, contributes to facilitate the generation and propagation of damage when subject to 
impact loads. In consequence, the threshold energy decreases up to $50 \%$ in quasi isotropic laminate when temperature falls from 20 to $150{ }^{\circ} \mathrm{C}$ to, as has been stated experimentally.

Fibre reinforcement architecture and stacking sequence play an essential role in the behaviour of CFRP composites under such thermal and loading conditions. Thermally induced effect is severe in tape laminates (cross ply and quasi isotropic), where orientation of the carbon fibres is different in each layer. In these materials, low temperatures produce interlaminar residual thermal stresses, high enough to accelerate matrix cracking during low velocity impact, with delamination of the composite material. In the plain woven laminate used in this study, where orientation of the fibres was parallel in each ply, thermal variation did not induce interlaminar stresses, and damage extension after impact did not increase substantially at low temperature.

\section{Acknowledgements}

The authors are indebted to the Spanish Comisión Interministerial de Ciencia y Tecnología (Project MAT 98/0273) for the financial support of this work, and to the Department of Engineering Science of the University of Oxford for their assistance in the C Scan inspection tests.

\section{References}

[1] Sun CT. Analytical method for evaluation of impact damage energy of laminated composites. In Fourth Conference on Composite Materials: Testing and Design, ASTM STP 617 T; 1977.

[2] Kellas S. Environmental effects on fatigue damage in notched carbon fiber composites. PhD Thesis, University of London; 1988.

[3] Cartié DR, Irving PE. Effect of resin and fibre properties on impact and compression after impact performance of cfrp. Composites Part A: Appl Sci Manuf 2002;33(4):483 93.

[4] Cantwell WJ, Morton J. The impact resistance of composite materials: a review. Composites 1991;22(5):347 62 .

[5] Abrate S. Impact on laminated composite materials. Appl Mech Rev 1991;44:155 90 .

[6] Abrate S. Impact on laminated composite: recent advances. Appl Mech Rev 1994;47(11):517 44.

[7] Bradshaw JC, Dorey G, Sidney GR. Impact resistance of carbon fibre reinforced plastics. Technical Report TR 72240 MOD, RAE; 1972.

[8] Kirk JR, Munro M, Beaumont PWR. The fracture energy of hybrid carbon and glass fibre composites. J Mater Sci 1978;13:2197 204.

[9] Beaumont PWR. Fracture mechanics: current status, future prospects. Chapter Fracture mechanics in fibrous composites, New York: Pergamon Press; 1979. p. 21133.
[10] Cantwell WJ, Morton J, Curtis PT. A study on the impact performance and subsequent 0 compression fatigue performance of non woven and mix woven composites. In: Morton J, editor. Structural impact and crashworthiness. Amsterdam: Elsevier; 1984.

[11] Ladevèze P, Lubineau G. On a damage mesomodel for laminates: micromechanics basis and improvement. Mech Mater 2003;35(8): 76375.

[12] Guinard S, Allix O, Guéedra Degeorges D, Vinet A. A 3d damage analysis of low velocity impacts on laminated composites. Compos Sci Technol 2002;62(4):585 9.

[13] Schutz JB. Properties of composite materials for cryogenic appli cations. Cryogenics 1998;38:3 12.

[14] Dutta PK, Faran KJ, Hui D. Influence of low temperature on energy absorption in laminated composites. In ICCM 9, vol. V; 1999. p. 31120 .

[15] Aoki T, Ishikawa T, Kumazawa H, Morino Y. Mechanical behaviour of cf/polymer composite laminates under cryogenic environment. In ICCM 12, vol. V; 1999.

[16] Reed RP, Golda M. Cryogenic properties of unidirectional compo sites. Cryogenics 1994;11:909 28.

[17] Pintado JM, Carrion JG, García JL, Blas F. Mechanical behavior of composite materials at cryogenic temperatures. In Proceedings of the Fourth European Conference Composites: Test Standard; 1998.

[18] Sánchez Sáez S, Gómez del Río T, Barbero E, Zaera R, Navarro C. Static behavior of CFRPs at low temperatures. Composites Part B: Eng 2002;33:383 90.

[19] Timmerman JF, Tillman MS, Hayes BS, Seferis JC. Matrix and fiber influences on the cryogenic microcracking of carbon fiber/ epoxy composites. Composites Part A: Appl Sci Manuf 2001;33: 3239.

[20] Kwang Hee I, Cheon Seok C, Sun Kyu K, In Young Y. Effects of temperature on impacts damages in cfrp composite laminates. Composites Part B: Eng 2001;32:669 82.

[21] López Puente J, Zaera R, Navarro C. The effect of low temperatures on the intermediate and high velocity impact response of CFRPs. Composites Part B: Eng 2002;33:559 66.

[22] Gao SL, Kim JK. Three dimensional characterization of impact damage in CFRPs. Key Eng Mater 1998;141 143:35 54.

[23] Burke SK, Cousland SM, Scala CM. Nondestructive characterization of advanced composite materials. Mater Forum 1994;18:85 109.

[24] Scott IG, Scala CM. A review of non destructive testing of composite materials. NDT Int 1982;

[25] Hatford DT, Henneke EG. A model for correlation damage and ultrasonic attenuation in composites. In Fifth Conference on Composite Materials: Testing and Design; 1979.

[26] Scarponi C, Brioti G, Barboni R. Impact testing on composite laminates and sandwich panels. J Compos Mater 1996;30(17): 1873911.

[27] Clark G. Modelling of impact damage in composite laminates. Composites 1989;20:209 14.

[28] Vietinghoff H. Compression after impact strength of carbon fiber reinforced plastic laminates. $\mathrm{PhD}$ Thesis, University of Carleton; 1993.

[29] Abrate S. Impact on composite structures. Cambridge: Cambridge University Press; 1998.

[30] Chung DDL. Carbon fiber composites. London: Butterworth/Heine mann; 1994. 